Cronfa - Swansea University Open Access Repository

This is an author produced version of a paper published in :

Cronfa URL for this paper:

http://cronfa.swan.ac.uk/Record/cronfa2015

http://dx.doi.org/10.1016/j.ijfatigue.2007.02.006

This article is brought to you by Swansea University. Any person downloading material is agreeing to abide by the terms of the repository licence. Authors are personally responsible for adhering to publisher restrictions or conditions. When uploading content they are required to comply with their publisher agreement and the SHERPA RoMEO database to judge whether or not it is copyright safe to add this version of the paper to this repository. http://www.swansea.ac.uk/iss/researchsupport/cronfa-support/ 
Elsevier Editorial System(tm) for International Journal of Fatigue

Manuscript Draft

Manuscript Number:

Title: Prediction of notched specimen behaviour at ambient and high temperatures in Ti6246

Article Type: Special Issue: Fatigue Damage VI

Section/Category:

Keywords: Titanium; Notches; Prediction; Walker

Corresponding Author: Dr Mark Thomas Whittaker, PhD

Corresponding Author's Institution: University of Wales Swansea

First Author: Mark Thomas Whittaker, PhD

Order of Authors: Mark Thomas Whittaker, PhD; William J Evans, PhD; Peter J Hurley, PhD; Dean Flynn

Manuscript Region of Origin: Europe

Abstract: 


\title{
Prediction of notched specimen behaviour at ambient and high temperatures in Ti6246
}

\author{
MT Whittaker, WJ Evans, PJ Hurley, D Flynn \\ University of Wales Swansea, Singleton Park, Swansea, UK. \\ m.t.whittaker@swansea.ac.uk
}

\begin{abstract}
Life prediction methods are essential in the selection of materials for high performance applications. These design criteria allow safe lives to be predicted for areas of geometrical discontinuity where localized increases in stress lead to the early initiation and propagation of fatigue cracks under cyclic loading. This paper explains two methods for predicting the initiation life of a double edged notch specimen $\left(\mathrm{K}_{\mathrm{t}}=1.9\right)$, and applies them to the $\alpha+\beta$ titanium alloy Ti6246 over a range of temperatures. The Coffin-Manson equation is effective for fully reversed cyclic behaviour. However a Walker strain-based parameter was found to be more appropriate when mean stresses are introduced. The analysis encompasses traditional analytical approaches which are limited in relation to the determination of the stresses and strains at the notch root and a finite element analysis based on ABAQUS. The FEA is used to characterize loop generation at the notches and to optimize the stress and strain conditions in the critical root positions.

The crux of the paper, however, is high temperature behaviour where creep and environmental damage impact on fatigue crack development. The limitations of the modelling approach under these conditions are discussed.
\end{abstract}

\section{INTRODUCTION}

Since the invention of the gas turbine engine over 50 years ago, significant improvements have been made in the mechanical properties of the high performance alloys. Many of the improvements have been made through enhanced chemistry and novel processing 
methods or through the refinement of existing processing methods to improve homogeneity and isotropy. However, it has become apparent that maintenance of this rate of progress will be difficult. As a consequence, one line of recent research is exploring the feasibility of extending operating conditions of existing alloys through improved quantification of crack development mechanisms and the introduction of more effective life prediction methods.

The alpha-beta titanium alloy Ti6246 is an example of a material which is currently under investigation at operating conditions that exceed original intentions. It is an alloy that is commonly used in compressor discs because of its combination of high strength to weight ratio and good temperature properties. Over the years, however, it has been required to operate at higher temperatures than originally intended because of the quest for increased efficiency. These temperature increases have led to a situation in which an approach based purely upon fatigue is no longer adequate in modelling the material properties. For temperatures above approximately $450^{\circ} \mathrm{C}$, the influence of creep mechanisms operating in the alloy can no longer be ignored. In addition environmental interactions considerably accentuate the design problems. The isolated fatigue and creep properties of the material are well understood. The aim of this work is to extend that understanding by investigating the material at temperatures and under operating conditions where creep and environmental interactions are important and where the more simplistic life prediction approaches are challenged.

To support the modelling activities a series of mechanical tests that included cyclic and dwell waveforms were carried out on Ti6246 over a wide range of temperatures. These tests provided the input information required for the analytical and FEA models. An important feature of these models is the assumption that material at the notch root experiences deformation conditions that are similar to those imposed during strain control testing of plain specimens. The experimental programme, therefore, focuses on the generation of strain-life data and hysteresis loop evolution in plain specimens and uses that information to construct the cyclic stress-strain characteristics for the alloy. The modelling work was applied to double edged notch (DEN, $\left.K_{t}=1.9\right)$ specimens which were also tested over a similar range of conditions. 
The Ti6246 used in the programme was tested in the as received condition, post thermo mechanical processing and subsequent heat treatments. This resulted in a material with a Widmanstätten microstructure and transformation texture typical of a titanium alloy processed above the beta transus temperature, Figure 1. The fatigue response of the material was known to be extremely sensitive to surface finish, and as such specimens were produced with a better than $0.05 \mu \mathrm{m}$ surface finish.

Strain control specimens of diameter $6 \mathrm{~mm}$ were tested to $\mathrm{BS} 7270^{[1]}$ on an ESH servo hydraulic test machine using a controlling MTS high temperature extensometer with a gauge length of $12 \mathrm{~mm}$. The experiments were completed using a standard trapezoidal waveform. Waveforms were adapted so that strain rates on loading and unloading were kept constant at $0.5 \% / \mathrm{sec}$. Cyclic tests were undertaken at $20^{\circ} \mathrm{C}, 450^{\circ} \mathrm{C}, 500^{\circ} \mathrm{C}$ and $550^{\circ} \mathrm{C}$ and $\mathrm{R}$ ratios of $-1,0$ and 0.5 . The $\mathrm{R}=-1$ tests provided open hysteresis loops for use in the modelling work. Stress-strain loops were recorded by an in-house data logging system which also allowed the recording of peak and minimum stresses so that a graph of stress relaxation as a function of cycles could also be recorded.

Fatigue tests on notch specimens were undertaken on a Mayes servo hydraulic test machine, and crack initiation was also measured by a standard potential drop technique ${ }^{[2]}$. Details of the tested double edge notch (DEN) specimen can be found in previous publications $^{[3]}$.

\section{RESULTS}

\section{Fatigue/Creep interactions}

The stabilised strain control loops from tests at $450^{\circ} \mathrm{C}, 500^{\circ} \mathrm{C}$ and $550^{\circ} \mathrm{C}$ are shown in Figure 2. Whilst the 1 second dwell period employed at peak strain during these tests is not long enough to show evidence of creep, associated dwell tests reveal that creep deformation is limited at $450^{\circ} \mathrm{C}$, but at $500^{\circ} \mathrm{C}$ there is a marked effect which becomes 
more significant at $550^{\circ} \mathrm{C}$. The fall off in stress for the stabilised loop at $550^{\circ} \mathrm{C}$ in Figure 2 is most likely due to this time dependent strain accumulation. The creep contribution was emphasised in previous work ${ }^{[4]}$ on stress-strain loops under $\mathrm{R}=0$ loading conditions. The consequence of the relaxation is evident from the cyclic stress-strain curve at $550^{\circ} \mathrm{C}$ in Figure 3. A similar effect is not evident at $500^{\circ} \mathrm{C}$.

The previous work also demonstrated that the strain life response of Ti6246, Figure 4 shows a distinct change in failure mechanism between high and low strains. This was attributed to the cracking of an oxide layer at higher strains that allowed the ingress of

environment ${ }^{[4,5]}$. Evidence of this environmental damage is also clear in the present work. Figure 5 illustrates this in the form of boundary cracking at $550^{\circ} \mathrm{C}$.

The current strain-life data at $\mathrm{R}=-1$ is consistent with the behaviour illustrated in Figure 4. Furthermore, it became clear that although there is a substantial effect on the stress relaxation characteristics, dwell periods of 2 minutes at peak strain do not significantly affect the specimen lives.

\section{Predicting notched specimen behaviour}

\section{The Coffin-Manson equation}

Aeroengine design engineers need to predict the fatigue performance of stress raising features within components. Established methods are frequently applied. One of the best known is the application of the Coffin-Manson equation.

The Coffin-Manson method ${ }^{[6,7]}$ requires the applied strain for $\mathrm{R}=-1$ strain control data to be partitioned into its elastic and plastic components, i.e.

$$
\Delta \varepsilon_{T o t}=C_{e} N_{f}^{\alpha 2}+C_{p} N_{f}^{\alpha 1}
$$

For the present alloy at room temperature these constants were determined to be $\mathrm{C}_{\mathrm{e}}=0.0361$ (Elastic constant) $\mathrm{C}_{\mathrm{p}}=1.0301$ (Plastic constant) 
$\alpha 1=-0.792$ (Plastic exponent)

$\alpha 2=-0.1233$ (Elastic exponent)

The strain at the notch root was initially calculated analytically by applying the Neuber method as shown in Figure 6. Neuber ${ }^{[8]}$ assumes that the material in the plastic zone at the notch root can be defined through redistribution from a hypothetical elastic line according to the relationship

$$
\text { Stress }(\sigma) \mathrm{x} \text { strain }(\varepsilon)=\text { constant }
$$

This redistribution process is shown by the hyperbolic curve $A B$ in Figure 6, with the stabilised condition defined where the curve crosses the cyclic stress-strain curve. The material was then considered to deform elastically, along the line $\mathrm{BC}$, with the minimum value determined by the applied stress state. This elastic unloading was imposed after examination of the $\mathrm{R}=0$ and $\mathrm{R}=-1$ stabilised hysteresis loops on plain specimens. The strain experienced at the notch root is fed back into the Coffin-Manson equation, to allow a predicted life to be determined by iteration.

The predictions made by this method for the DEN specimen are shown in Figure 7. It can be seen that a good correlation is found for the $\mathrm{R}=-1$ loading conditions. It should be noted that predicted notch lives are based on initiation only. In a strain control specimen, once a crack forms it propagates quickly to failure. In a notched specimen, the crack travels through material experiencing stresses considerably lower than the notch root. Consequently a significant propagation phase should be considered for the notched specimen. Through the PD monitoring of the specimens, it was found that a $2 \mathrm{~mm}$ crack formed between $80-90 \%$ of the life of the specimen. Assuming a $20 \%$ propagation phase in the notch specimen results in excellent life predictions.

However, the Coffin-Manson considerably overestimates the $\mathrm{R}=0$, DEN experimental data. Although the plastic deformation at the notch root forces the unloading into compression, its magnitude is not enough to avoid a tensile mean stress which is an important factor in the overprediction of lives. It is interesting to note that for a sharper, $\mathrm{V}$-cylindrical notch at $\mathrm{R}=0$, the notch root settles down to an approximate $\mathrm{R}=-1$ cycle, and the Coffin-Manson equation provides more accurate predictions. 
A modified version of the equation has been proposed by Duggan ${ }^{[9]}$ to take account of mean stress.

$$
\Delta \varepsilon_{T}=\left(\varepsilon_{f}^{\prime}-\varepsilon_{m}\right) N_{f}^{\alpha_{1}}+C_{e}\left(1-\frac{\sigma_{m}}{\sigma_{U T S}}\right) N_{f}^{\alpha_{2}}
$$

where $\varepsilon_{f}{ }^{\prime}$ is the fatigue ductility coefficient, $\varepsilon_{\mathrm{m}}$ and $\sigma_{\mathrm{m}}$ are the mean strain and mean stress respectively and $\sigma_{\mathrm{UTS}}$ is the tensile strength of the material.

Application of this equation to the $\mathrm{R}=0$ notch data is illustrated in Figure 7. The equation underpredicts, although the results are encouraging. However, at higher temperatures where mean stress effects become more important the underprediction becomes excessive, Figure 8 . An alternative approach is clearly necessary.

\section{The Walker strain method}

The Walker strain method is a widely used approach for quantifying mean stress effects through an empirical technique of correlating $\mathrm{R}$ value data ${ }^{[10]}$. This is achieved through the expression

$$
\Delta \varepsilon_{w}=\frac{\sigma_{\max }}{E}\left(\frac{\Delta \varepsilon E}{\sigma_{\max }}\right)^{m}
$$

where; $\Delta \varepsilon_{\mathrm{w}}=$ Walker strain

$$
\begin{aligned}
& \sigma_{\max }=\text { maximum stabilised stress } \\
& \mathrm{E}=\text { Modulus } \\
& \Delta \varepsilon=\text { strain range } \\
& \mathrm{m}=\text { Walker exponent }
\end{aligned}
$$

The strain control data produced for different $\mathrm{R}$ ratios is first correlated using an appropriate $\mathrm{m}$ value. This was determined to be 0.45 at room temperature for the present material. Curve fitting the correlated data gives the expression 


$$
\Delta \varepsilon_{w}=0.0346 \mathrm{~N}_{\mathrm{f}}^{-0.1525}
$$

Once again the stress-strain conditions at the notch root are determined by the Neuber rule. From the maximum stabilised stress and strain range a Walker strain was calculated for the notched specimen. Rearrangement of equation (5) then allows notch lives to be predicted.

The predictions at room temperature from the Walker method are recorded in Figure 7. It is evident that for both $\mathrm{R}=-1$ and $\mathrm{R}=0$ notches that the predictions are relatively accurate although there is a tendency to overpredict in the latter case.

\section{Predictions at high temperature}

At room temperature, therefore, the Walker strain and modified Coffin-Manson techniques provide acceptable predictions of lives for $\mathrm{R}=0$ notched specimens. At $450^{\circ} \mathrm{C}$ however, the modified Coffin-Manson technique is not as effective as the Walker relationship, Figure 8.

However, whilst the Neuber method of determining stress and strain at the notch root is a useful approximation, improved precision demands that more powerful techniques are used to characterise the complex deformation conditions. The development of a model within the ABAQUS FEA suite allowed this to be achieved. Based on the analytical approach, it was decided to focus specifically on the Walker method in the determination of notched specimen lives.

\section{Model development}

The production of stress-strain loops at various temperatures was essential to the work since these not only aided in the investigation of fatigue/creep interactions but also form the basis of predictive models in ABAQUS. The model was based upon the fact that under strain control conditions, localised stress redistribution processes allow the bulk stress in the specimen to stabilise to essentially constant peak and minimum stress 
conditions during the early cycles of the test. From experimental data the required cyclic stress-strain behaviour of the material was defined. The model used the $\mathrm{Mroz}^{[11]}$ multilayer kinematic hardening approach through application of a user subroutine within ABAQUS. A series of FE simulations of the strain control specimens were run using the Mroz user-subroutine to demonstrate how the initial loading ramp and the stabilised hysteresis loops may be modelled with sufficient accuracy at ambient and elevated temperatures. Figure 9 shows an example of these simulations and the ability of the method to account for the Baushinger effect evident in this material. It should be noted that the current model does not allow for time dependent effects (i.e. creep) at the higher temperatures. Whilst creep would not be expected to greatly affect the shape of the loops it would have a large effect in the presence of mean stresses. This is an issue that will be addressed later in the paper.

Modelling of the Double Edged Notch $\left(\mathrm{K}_{\mathrm{t}}=1.9\right)$ specimen was achieved through the construction of a three dimensional 1/8 symmetrical FE model using 20-noded isoparametric rectangular elements (C3D20) with 18833 nodes and 4032 elements. The element size was reduced closer to the notch root so that the mechanical response could be more accurately described in this region. Fatigue calculations were based on the stabilised stress-strain conditions at the node adjacent to the centre of the notch root.

The effectiveness of the method can be seen in Figure 10, where there is good correlation between predictions and results for room temperature. The method was then applied to higher temperature data, Figure $11\left(450^{\circ} \mathrm{C}\right)$ and Figure $12\left(550^{\circ} \mathrm{C}\right)$. It can be seen that both the analytical method and the ABAQUS prediction give accurate predictions at $450^{\circ} \mathrm{C}$. At $550^{\circ} \mathrm{C}$ however, the analytical method overpredicts the results, although the ABAQUS predictions are again accurate.

\section{DISCUSSION}

There is clear evidence that creep deformation becomes a major factor in Ti6246 at temperatures greater than $450^{\circ} \mathrm{C}$. Previous data supports this conclusion ${ }^{[4]}$ and shows that for higher temperatures, kinematic softening occurs for strain control testing at $\mathrm{R}=0$ conditions. The current work demonstrates similar occurrences under $\mathrm{R}=-1$ loading 
conditions. This time dependent strain accumulation is better illustrated by a 2 minute dwell period at peak tensile strain. The results shown in Figure 13 indicate that though there is some stress relaxation due to creep deformation at $500^{\circ} \mathrm{C}$ it is more extensive at $550^{\circ} \mathrm{C}$. It is interesting to note some of the effects this creep strain may have. Figure 14 shows the fatigue performance of DEN specimens at $450^{\circ} \mathrm{C}, 500^{\circ} \mathrm{C}$ and $550^{\circ} \mathrm{C}$. It is evident that as the temperature increases from $450^{\circ} \mathrm{C}$ to $500^{\circ} \mathrm{C}$ there is an improvement in fatigue life, despite a decrease in static mechanical strength. However, on increasing the temperature to $550^{\circ} \mathrm{C}$ there is a considerable reduction in fatigue life.

FEA has indicated that creep deformation at the notch root may play a major part in this anomaly. It is likely that the increased creep deformation around the notch root at $500^{\circ} \mathrm{C}$ leads to enough stress relaxation that the peak stresses at this temperature are lower than at $450^{\circ} \mathrm{C}$. Hence the improvement in life at $500^{\circ} \mathrm{C}$. However the larger accumulation of creep strain in the notch root and net section at $550^{\circ} \mathrm{C}$ leads to a significant reduction in life. In fact in associated crack propagation testing, specimens were found to fail by net section stress rupture away from the machined notch at this temperature.

While numerous methods of predicting notch behaviour are available, the paper has focused on the Coffin-Manson and Walker techniques. The Coffin-Manson is based on $\mathrm{R}=-1$ strain control data, and as such is very effective at predicting the behaviour of notched specimens where there is fully reversed loading at the notch root. Indeed, under particular conditions at the notch root this method can be effective for other $\mathrm{R}$ ratios. This is shown by the fact that a sharper V-Cylindrical notch with a $\mathrm{K}_{\mathrm{t}}$ of 2.8 matched the predictions of the Coffin-Manson method despite being under $\mathrm{R}=0$ loading conditions. The geometry of the notch means that the root stress shakes down to an almost fully reversed state.

Long standing mean stress modifications to the Coffin-Manson equation showed promise at room temperature, but underpredicted at higher temperatures. However the Walker strain method is an effective prediction tool at both room temperature $(\mathrm{R}=-1 \& \mathrm{R}=0)$ and $450^{\circ} \mathrm{C}(\mathrm{R}=0)$. Furthermore it was shown that analytical techniques, such as the Neuber rule for stress/strain redistribution at the notch root could give reasonable predictions. However, the complex stress conditions in the notch require a more accurate stress analysis approach. 
FEA predictions based on Walker appear to give good results. The room temperature predictions are excellent, and clearly the Walker technique benefits from a more accurate description of the stress and strain state at the notch root. Good results are also found at $450^{\circ} \mathrm{C}$, for both the analytical method and the FEA approach although the latter also provides a better description of the shape of the fatigue curve.

At $550^{\circ} \mathrm{C}$ there is a distinct difference between FEA and analytical predictions. At first glance it would seem that the FEA model is effective. This however is fortuitous and brought about by two conflicting factors.

The first factor associated with this is shown in Figure 15 which shows a comparison of different criteria at $500^{\circ} \mathrm{C}$ from previous work ${ }^{[12]}$, including Walker, Smith-WatsonTopper and a strain energy approach. There is clearly a marked difference between the Walker FEA approach and the other methods. This difference is probably associated with the fact that in Walker strain calculations allowance is made for multi-axial stresses through the von Mises criterion whereas axial stresses only are used for other calculations. At $500^{\circ} \mathrm{C}$, as already discussed, the alloy has become susceptible to creep deformation. This leads to significant stress redistribution and modification of the three dimensional stress state at the notch root. Inadequate modeling of these conditions is clearly a limitation. The successful prediction of the other approaches, however, are probably also fortuitous because they also do not correctly model notch root conditions. A second contributing factor is the relationship between the notched specimens and the strain control stress-strain conditions. At high temperatures the stresses involved in strain control tests shake down towards a fully reversed loading state. In the notch specimen, however, the net section is experiencing load control deformation at $\mathrm{R}=0$ so that there is some creep extension in the tensile direction for each cycle. Due to this increase in specimen length, there is more inelastic strain accumulated in the tensile loading direction compared with the compressive direction. Consequently the specimen acquires a tensile mean stress which contributes to a reduction in fatigue life when compared with the strain control specimens. This creep deformation causes the material at the notch root at high temperatures to behave in a different way to the uniform cross section in strain control specimens. Therefore the use of strain control data leads to an overprediction of notched specimen lives. 
Figure 12 for predictions at $550^{\circ} \mathrm{C}$ is interesting because it separates the two contributing factors quite clearly. The analytical technique is based upon axial stresses and therefore overpredicts because of the accumulation of creep strain at the notch. The FEA model does not at present incorporate creep deformation and should therefore experience a similar problem. However, this is counteracted by the difficulties involved in calculating the von Mises stresses, so by chance an apparent accurate prediction is obtained. Clearly there is now an urgent requirement to incorporate creep deformation and damage models into the fatigue life prediction method.

\section{CONCLUSIONS}

- Creep deformation can have a significant effect on the fatigue properties of Ti6246, through reductions in the peak stress at the notch root and consequently an increase in fatigue life.

- The Coffin-Manson approach to notch life prediction is effective in Ti6246 for fully reversed notched specimens and $\mathrm{R}=0$ testing in sharper notched specimens where loading at the notch root tends towards a fully reversed loading state.

- The Walker strain method of predicting notched specimen behaviour is consistently more accurate in the determination of notched specimen lives for loading conditions imposed over a range of temperatures.

- The Walker strain technique used in the FE analysis is accurate only for temperatures where creep deformation is limited. Above these temperatures difficulties in calculating the von Mises stress reduces its effectiveness.

- The Walker strain technique overpredicts at high temperatures due to creep deformation at the notch root, which results in a mean stress that reduces the experimentally determined specimen lives.

\section{ACKNOWLEDGEMENTS}

The authors would like to thanks Rolls-Royce plc for funding over the course of this work, and specifically Mr. Steve Williams for his help in the work. 


\section{REFERENCES}

[1] BS7270, "British standard method for constant amplitude strain controlled fatigue testing", British Standards Institution

[2] M.A. Hicks, A.C. Pickard, "A comparison of theoretical and experimental methods of calibrating the electrical potential drop technique for crack length determination", International Journal of Fracture 20 (1982) pp 91-101

[3] WJ Evans, MR Bache, PJ Nicolas, "The prediction of fatigue life at notches in the near alpha titanium alloy Ti834", International Journal of Fatigue 23 (2001) pp103-109

[4] WJ Evans, JP Jones, S Williams, "The interactions between fatigue, creep and environmental damage in Ti6246 and Udimet 720Li”, International Journal of Fatigue 27 (2005) pp1473-1484

[5] S Mailly "Effects de la temperature et d'l'environment sur la resistance a la fatigue d'alliages de titane" PhD thesis, L'Universite de Poitiers, 1999

[6] LF Coffin, Fatigue at High Temperatures, ASTM STP520 744-782,1973

[7] SS Manson, J. Experimental Mechanics, Vol. 5, No 7., 193-226,1965

[8] H Neuber, Transactions, ASME ,Journal of Applied Mechanics, 544-550, 1968

[9] TV Duggan, J Byrne, “Fatigue as a Design Criterion”, McMillan Press Ltd, 1977

[10] K Walker, Effects of Environment and Complex Loading History on Fatigue Life, ASTM STP 462, 1-14, 1970

[11] Mroz, Z. (1969) Acta Mech. 7, 199.

[12] PJ Hurley, MT Whittaker, S Williams, WJ Evans "Prediction of LCF lives in DEN specimens based on strain-control testing of plain Ti6246 specimens", $9^{\text {th }}$ Int. Fatigue Congress, Atlanta, 2006 
Figure 1: Microstructure and texture of tested material

Click here to download high resolution image
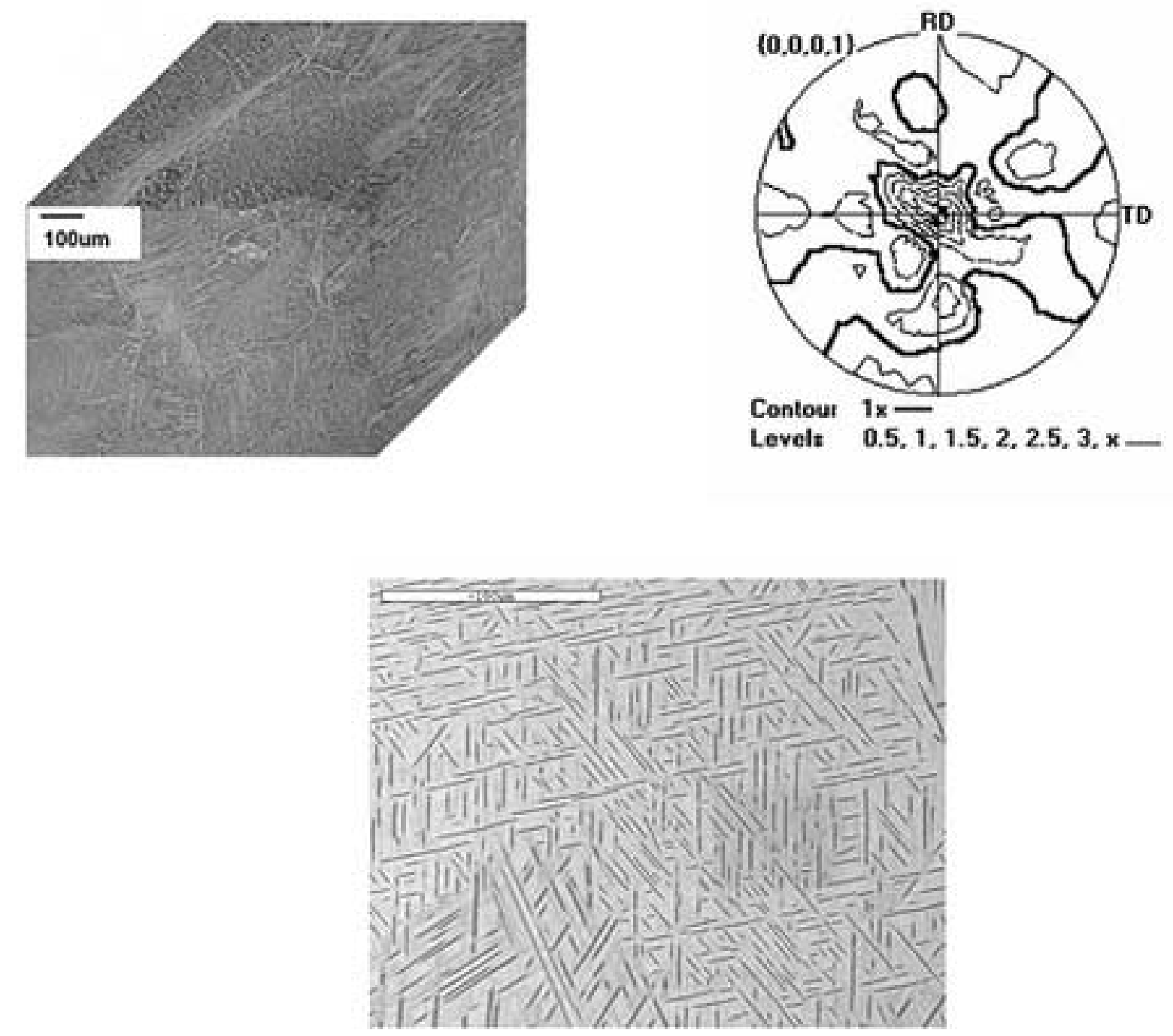

Levelt $\quad 0.5,1,1.5,2,2.5,3, x-$

.


Click here to download high resolution image

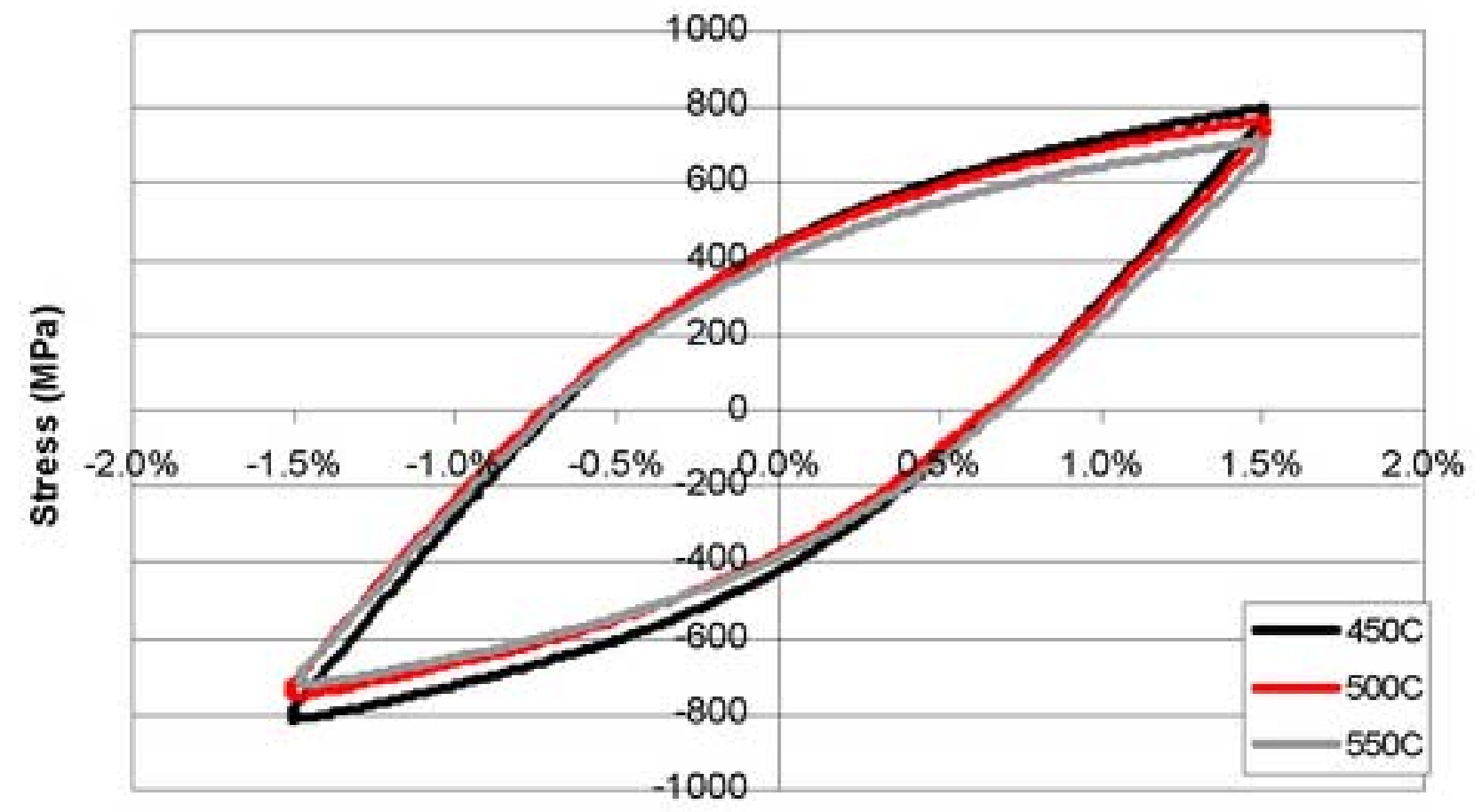

Strain

Figure 2: Stabilised $<$ sigma $>-<$ epsilon $>$ curves at high temperature 

Click here to download high resolution image

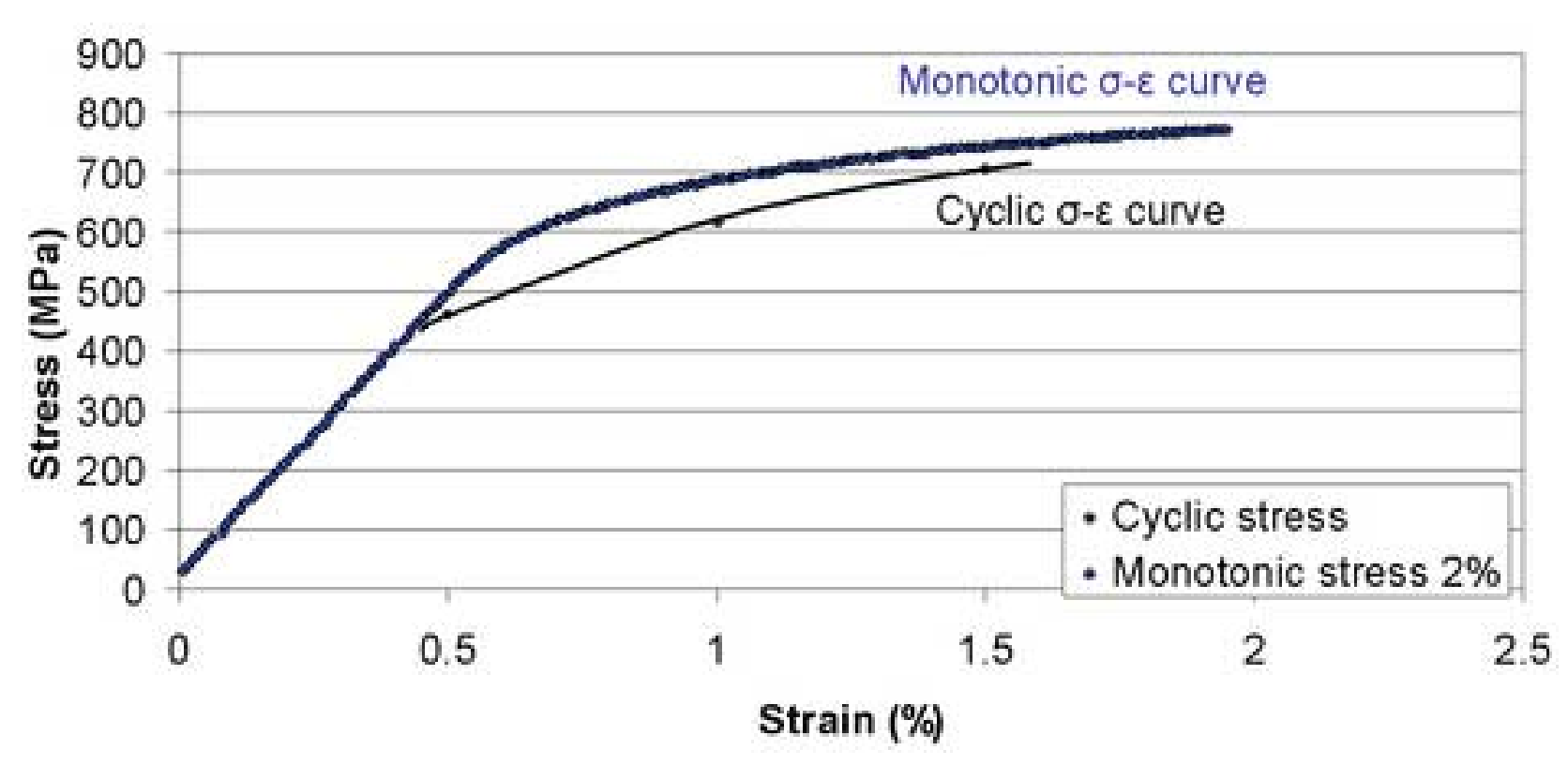

Figure 3: Cyclic and monotonic <sigma $>-<$ epsilon $>$ curves at $550^{\circ} \mathrm{C}$ Clck here to download high resoluton image 
Figure 4: Strain-life of Ti6246
Click here to download high resolution image

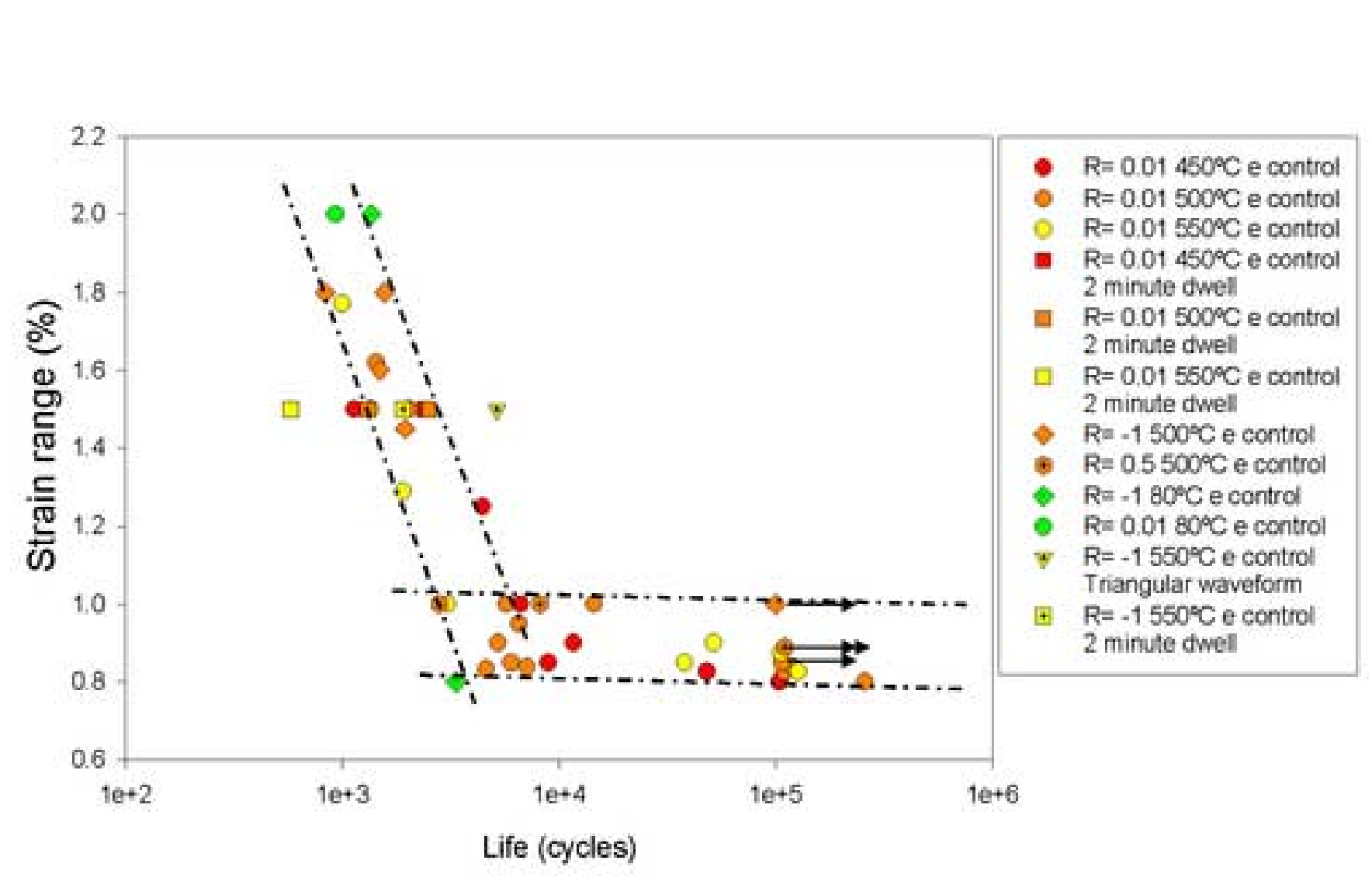


Click here to download high resolution image

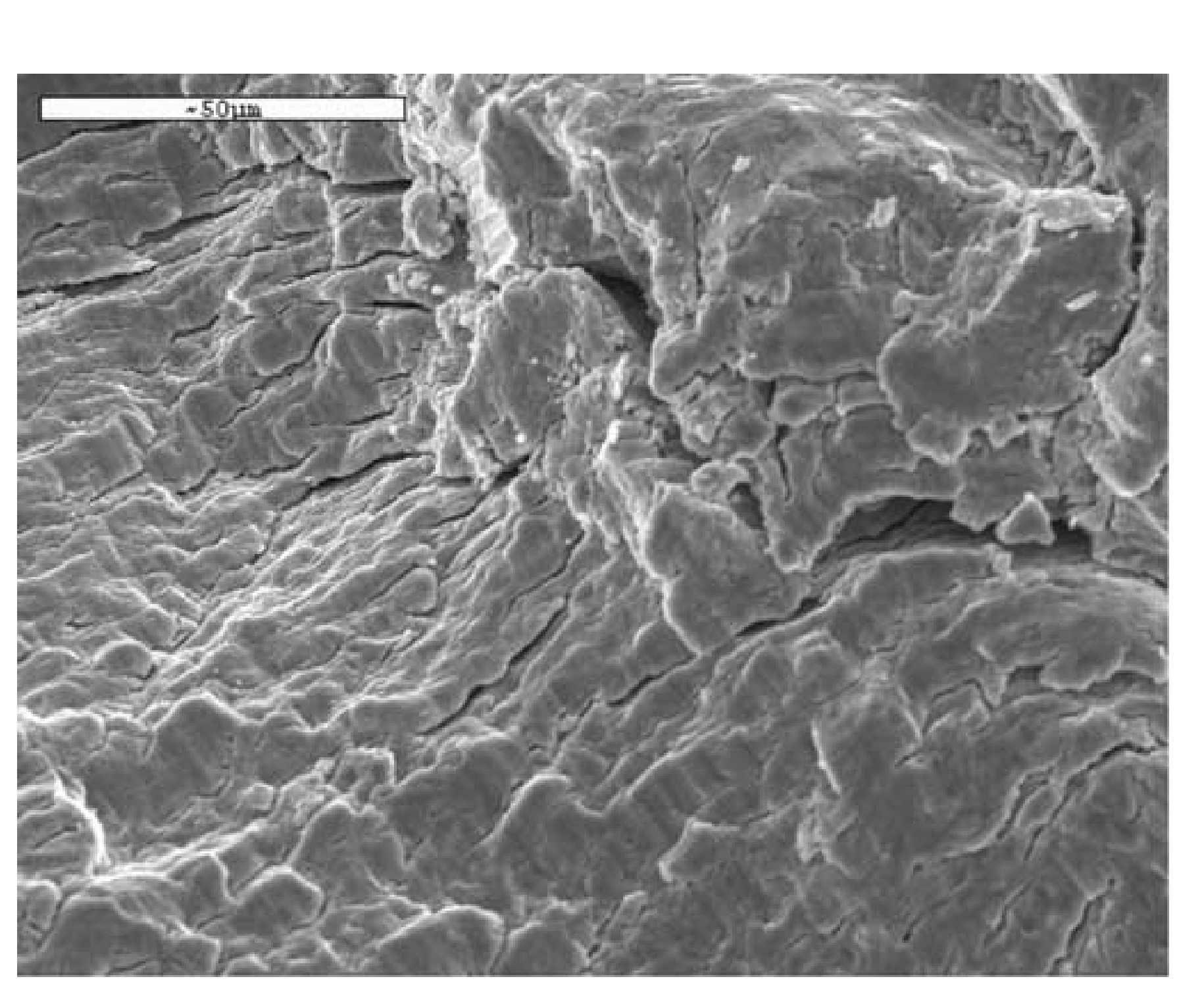

Figure 5: Cracking due to environmental ingress at $550^{\circ} \mathrm{C}$

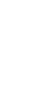

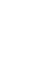

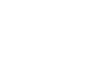

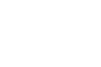

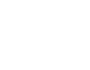

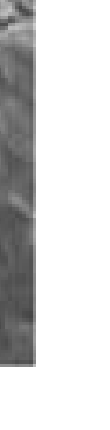

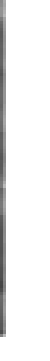 \\ .}

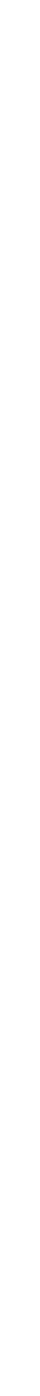


Figure 6: Description of the notch root
Click here to download high resolution image
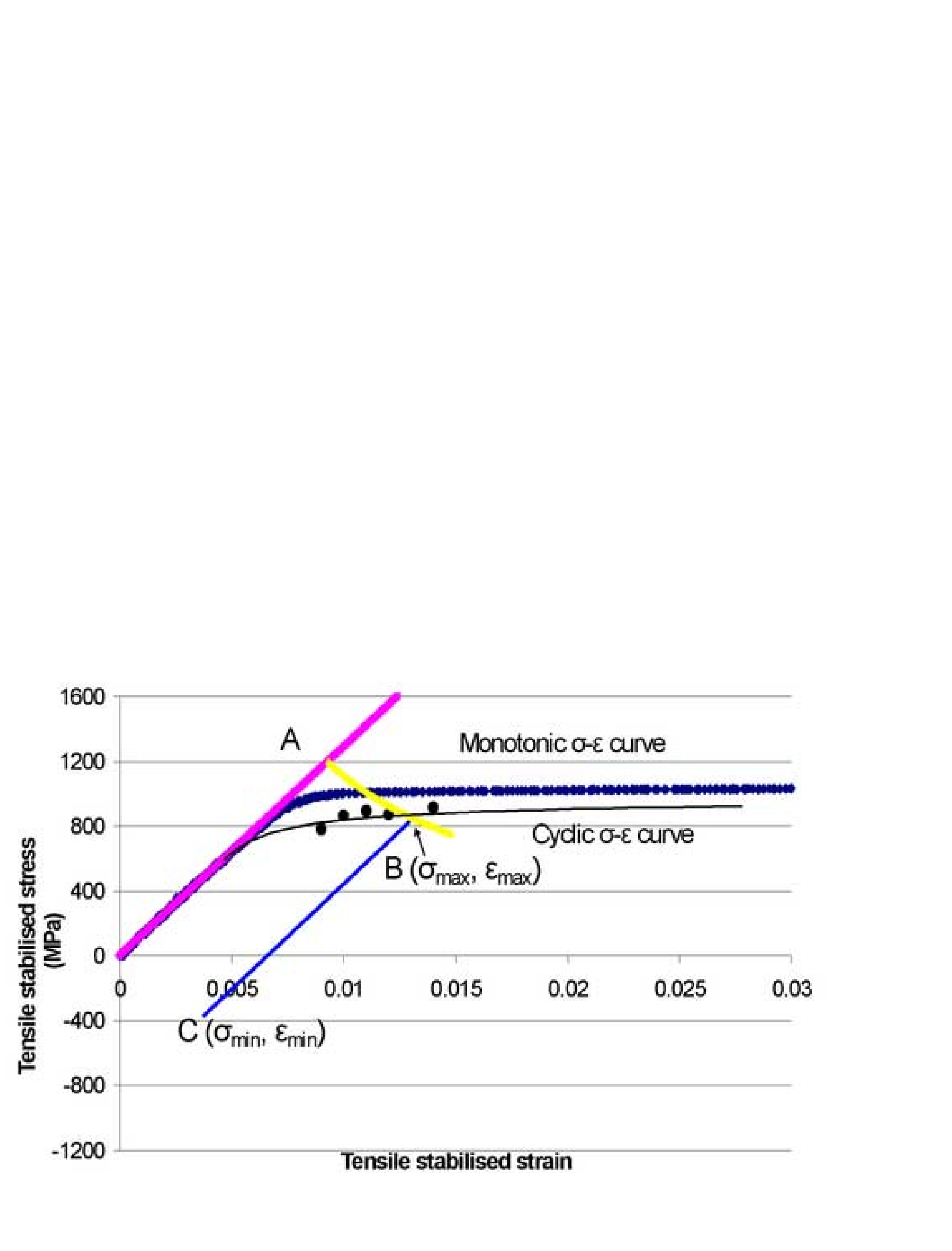

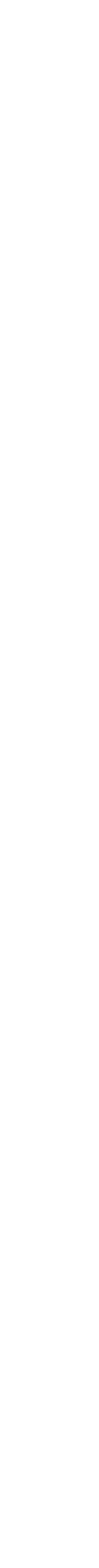


Click here to download high resolution image

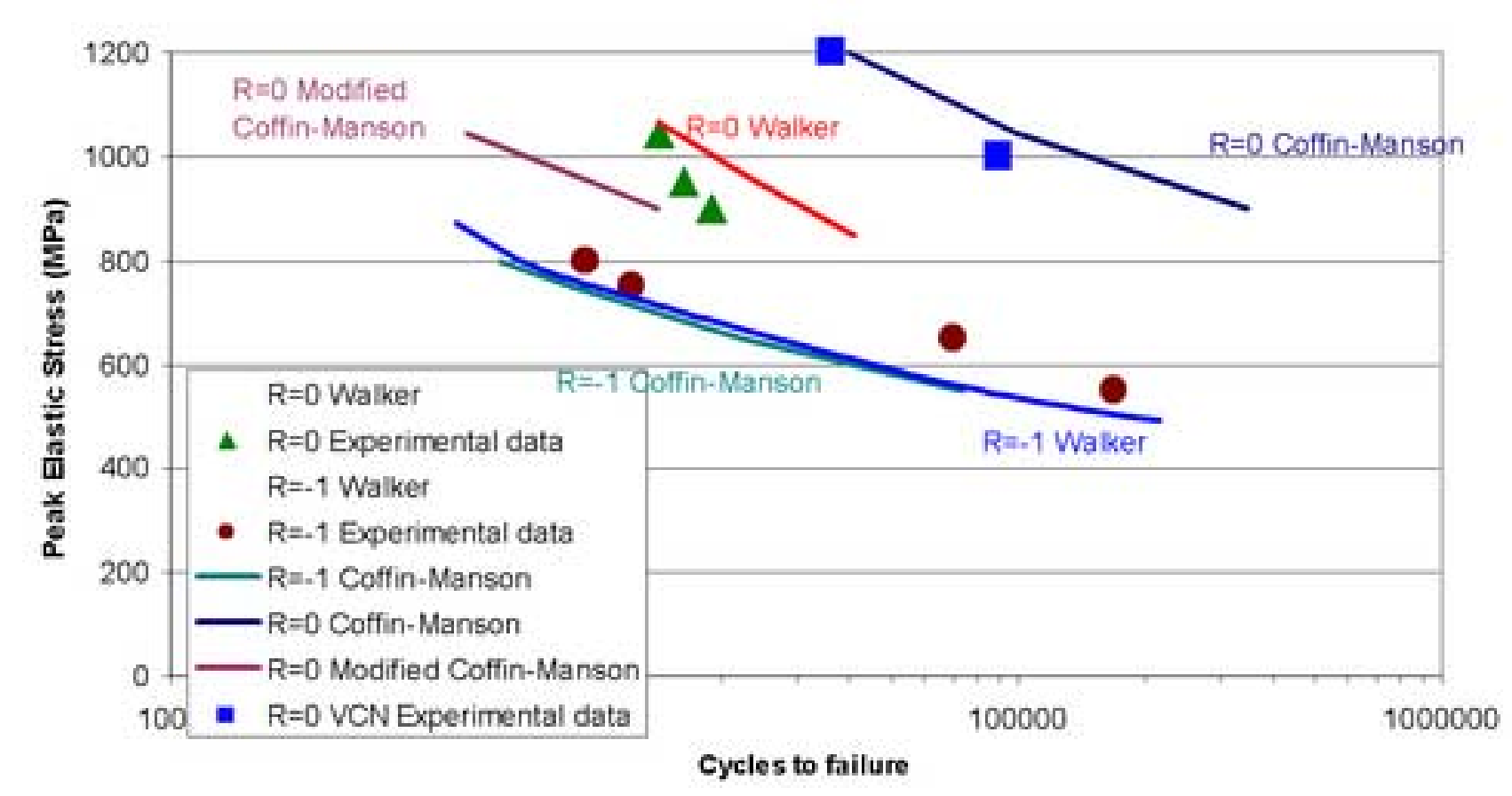
Figure 7: Predicted lives at $20^{\circ} \mathrm{C}$
Click here to download high resc

\section{ge}

ge

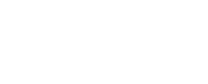
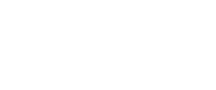

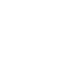

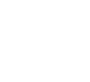

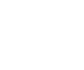

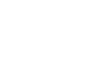

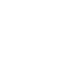

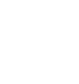
列

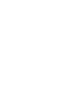

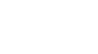
(2.

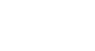

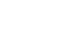

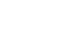

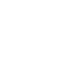

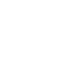

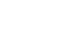

Cycles to failure

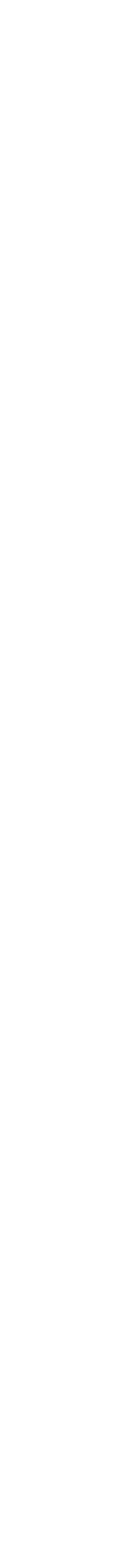


Click here to download high resolution image

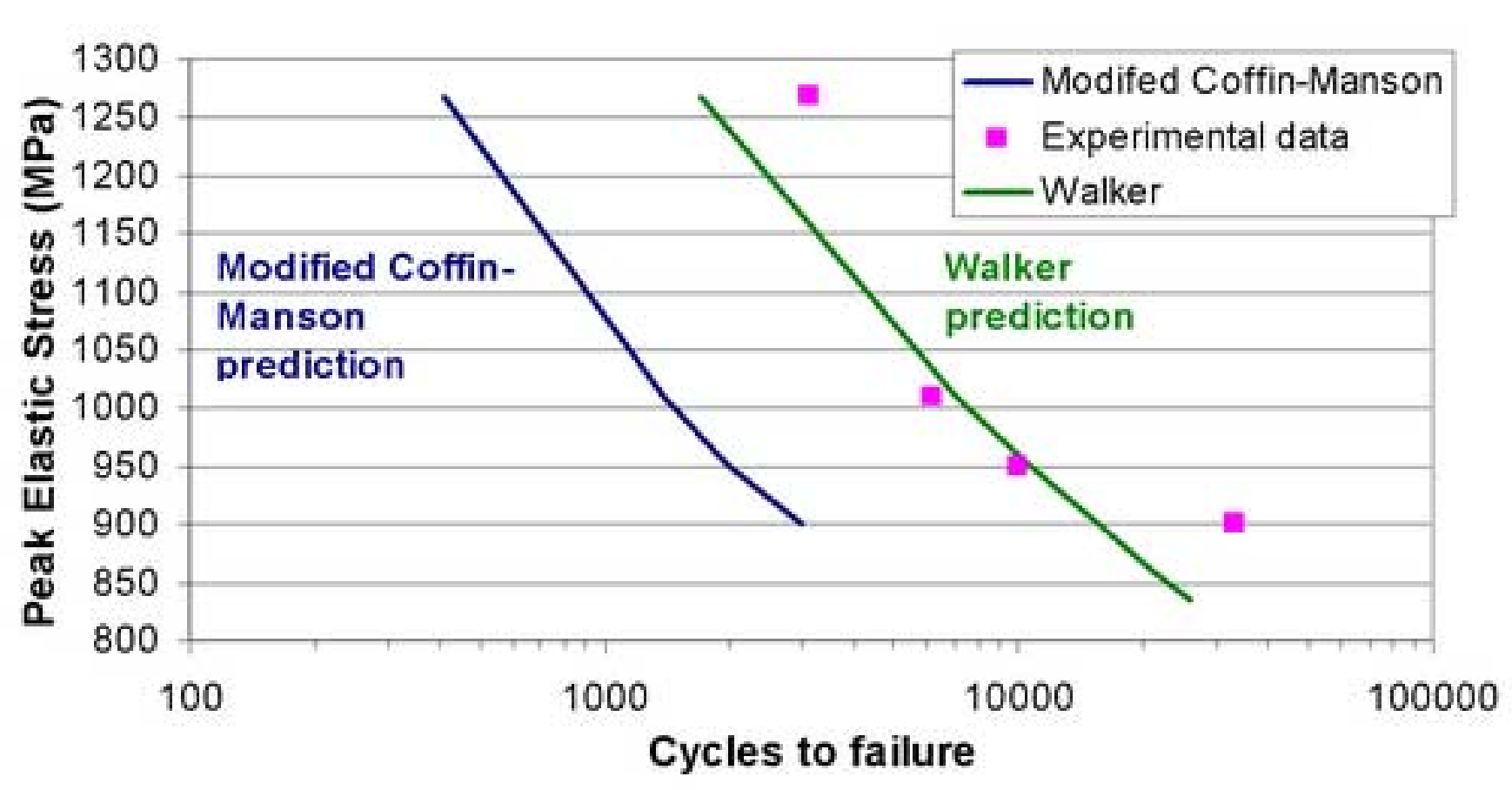

Figure 8: Comparison of methods at $450^{\circ} \mathrm{C}$

Clck here to download high resolution image

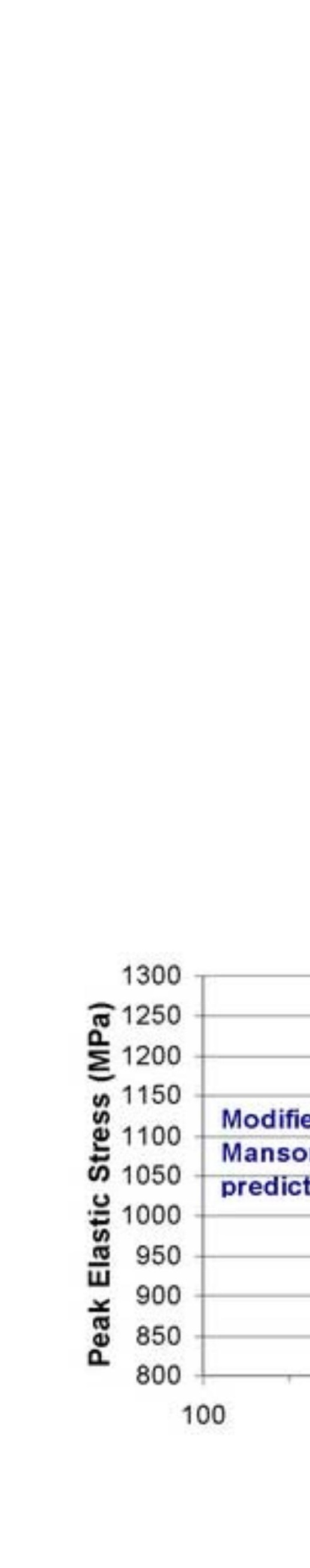

\section{e

列


Figure 9: ABAQUS modelling of <sigma $>-<$ epsilon > loop

Click here to download high resolution image

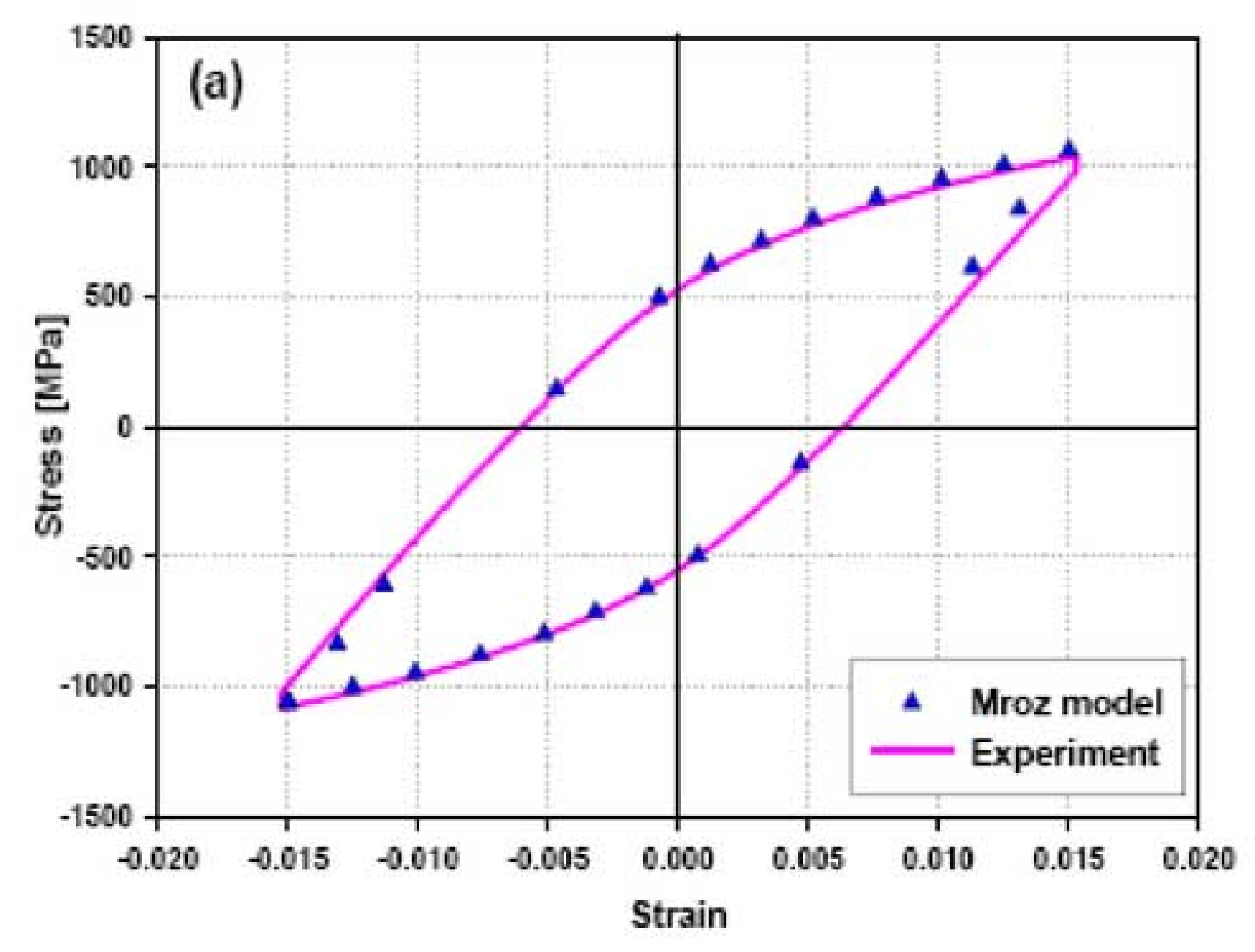

Click here to download high resolution image

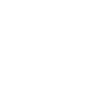

gsilon> loop

ge


Figure 10: ABAQUS predictions at $20^{\circ} \mathrm{C}$
Click here to download high resolution image

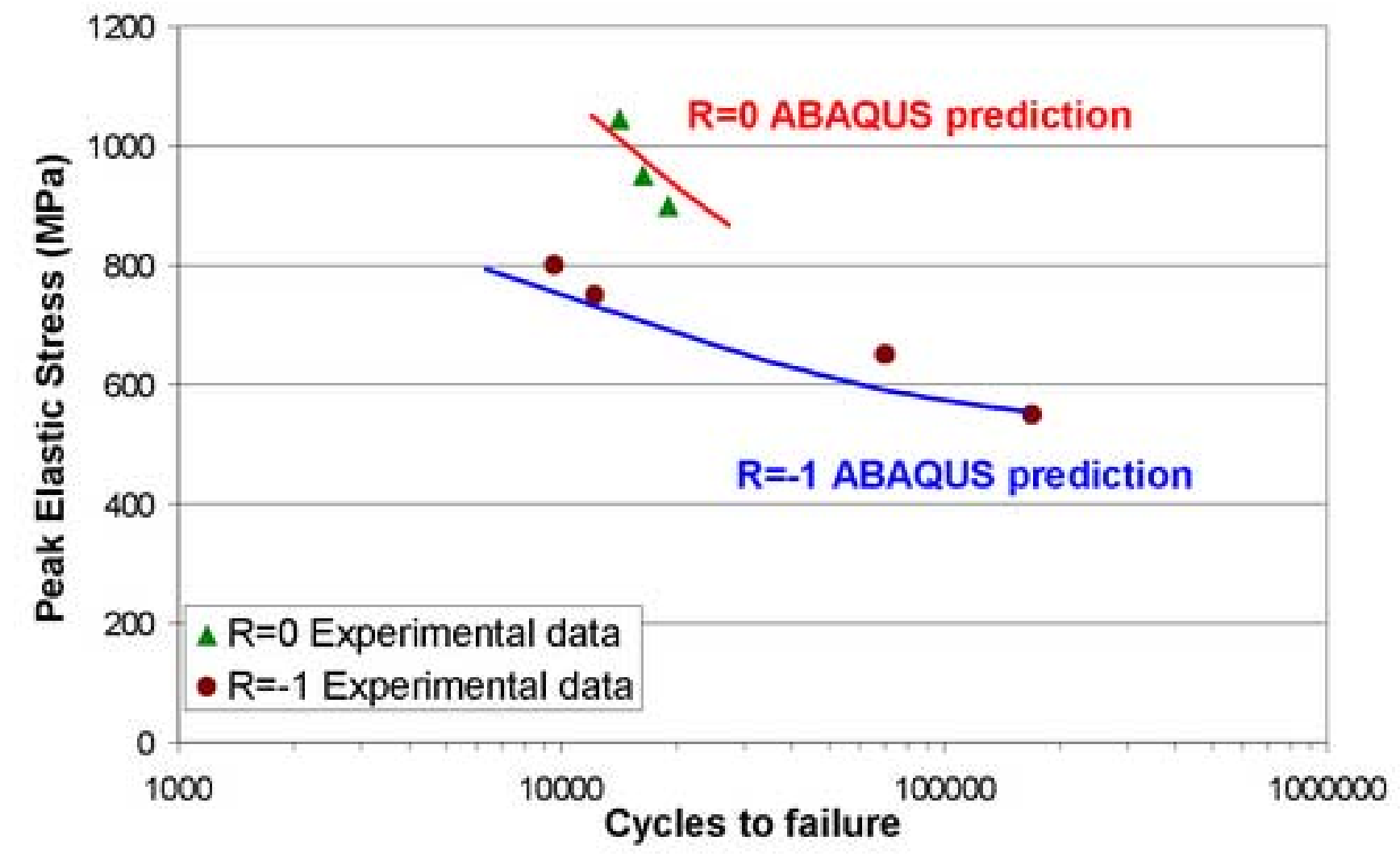


Figure 11: Walker predictions at $450^{\circ} \mathrm{C}$
Click here to download high resolution image

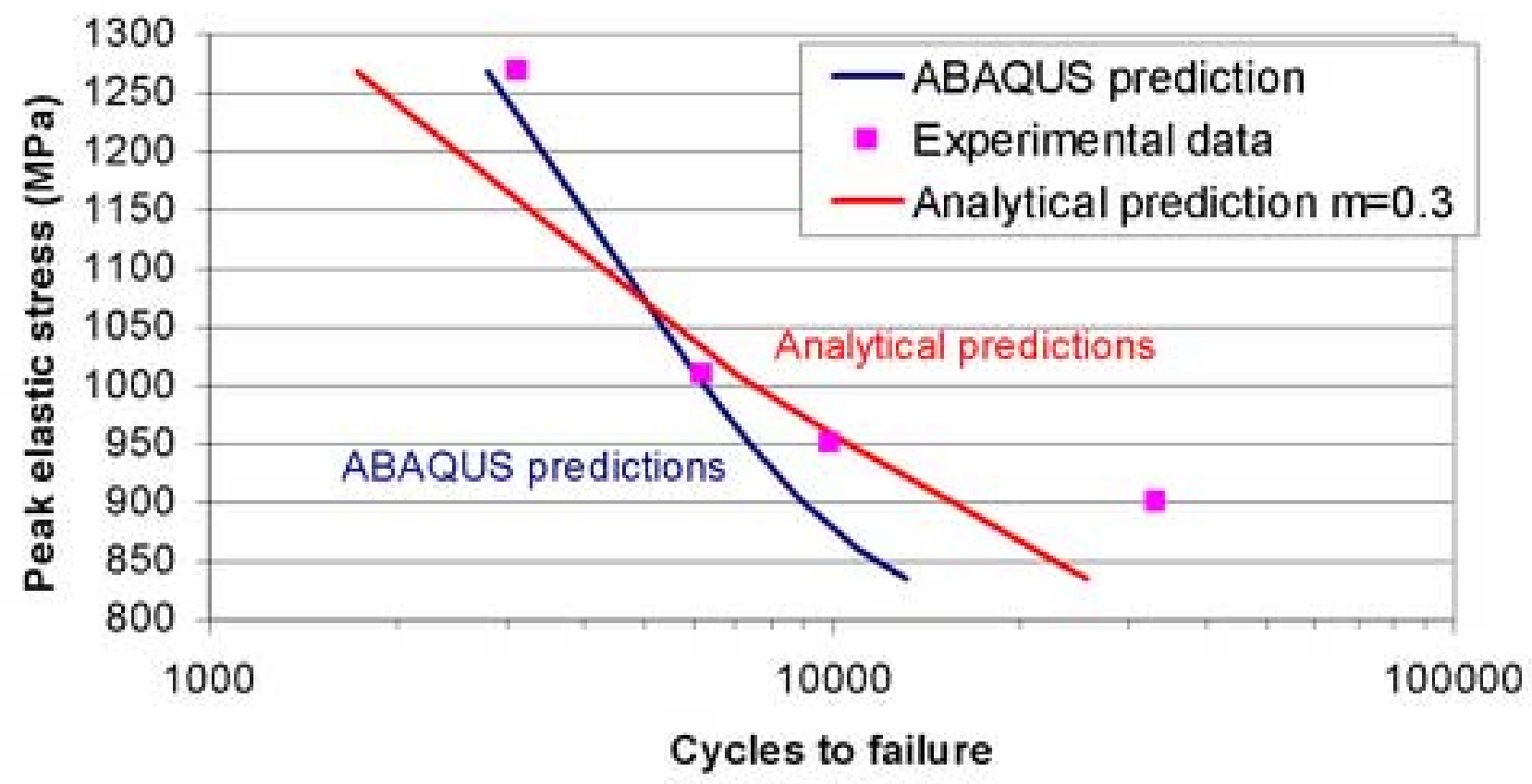


Figure 12: Walker predictions at $550^{\circ} \mathrm{C}$
Click here to download high resolution image

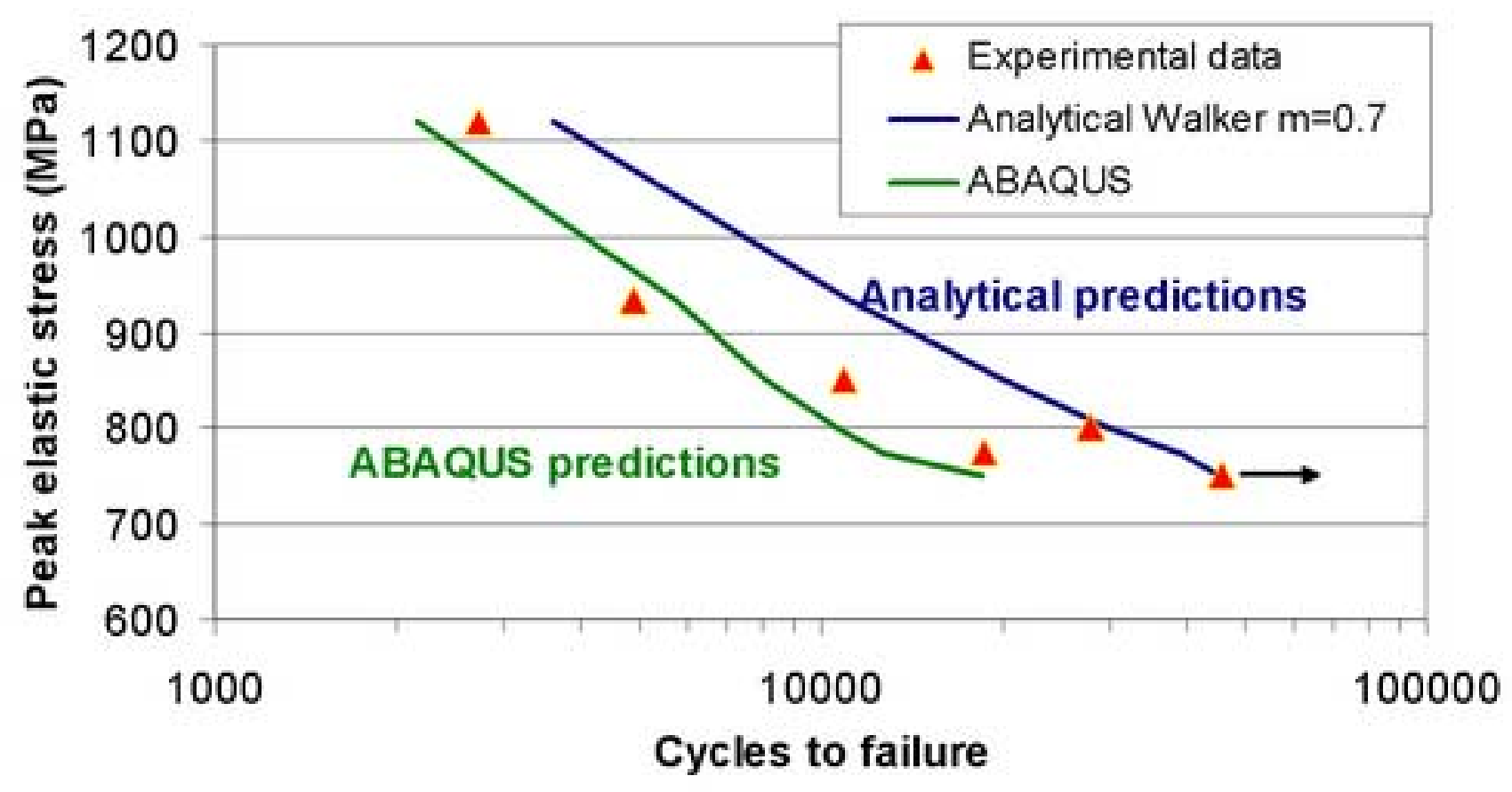


Figure 13: Stress relaxation during a 2 minute dwell period Click here to download high resolution image

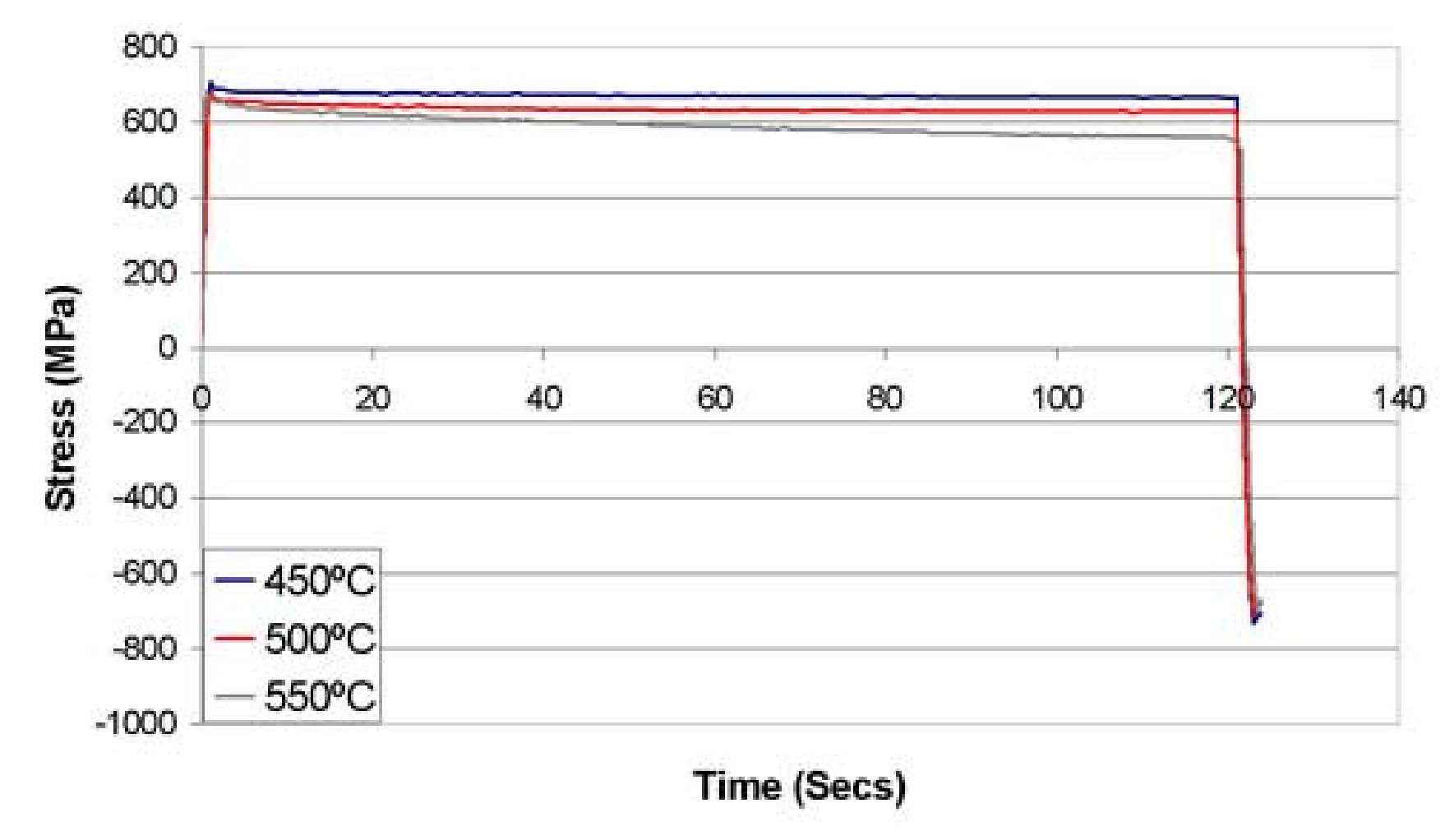
Click here to download high resolution image 

Click here to download high resolution image

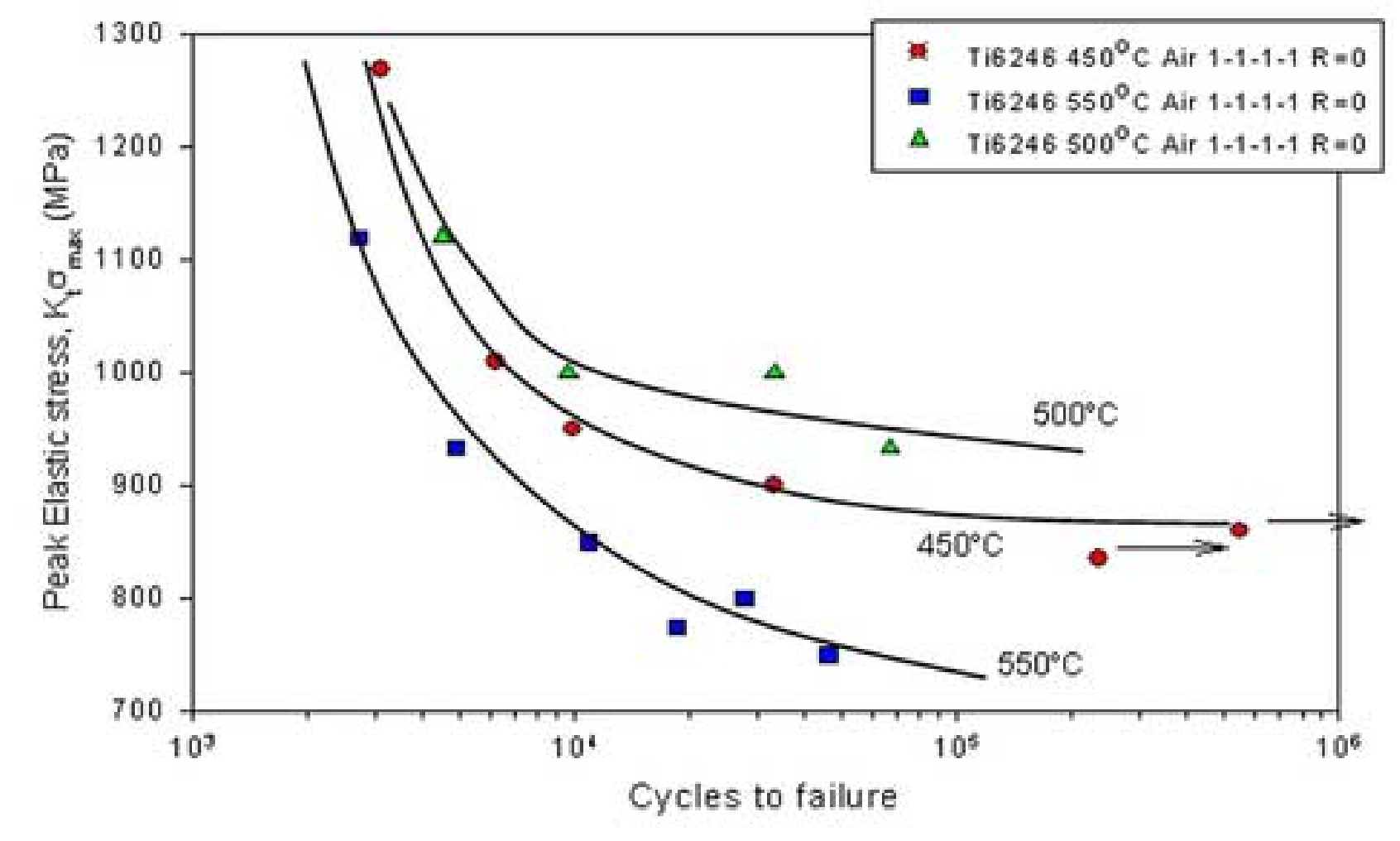

Figure 14: Fatigue results in DEN specimens

\author{
Click here to download high resolution image
}

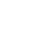


Figure 15: Various prediction methods at $500^{\circ}$
Click here to download high resolution image

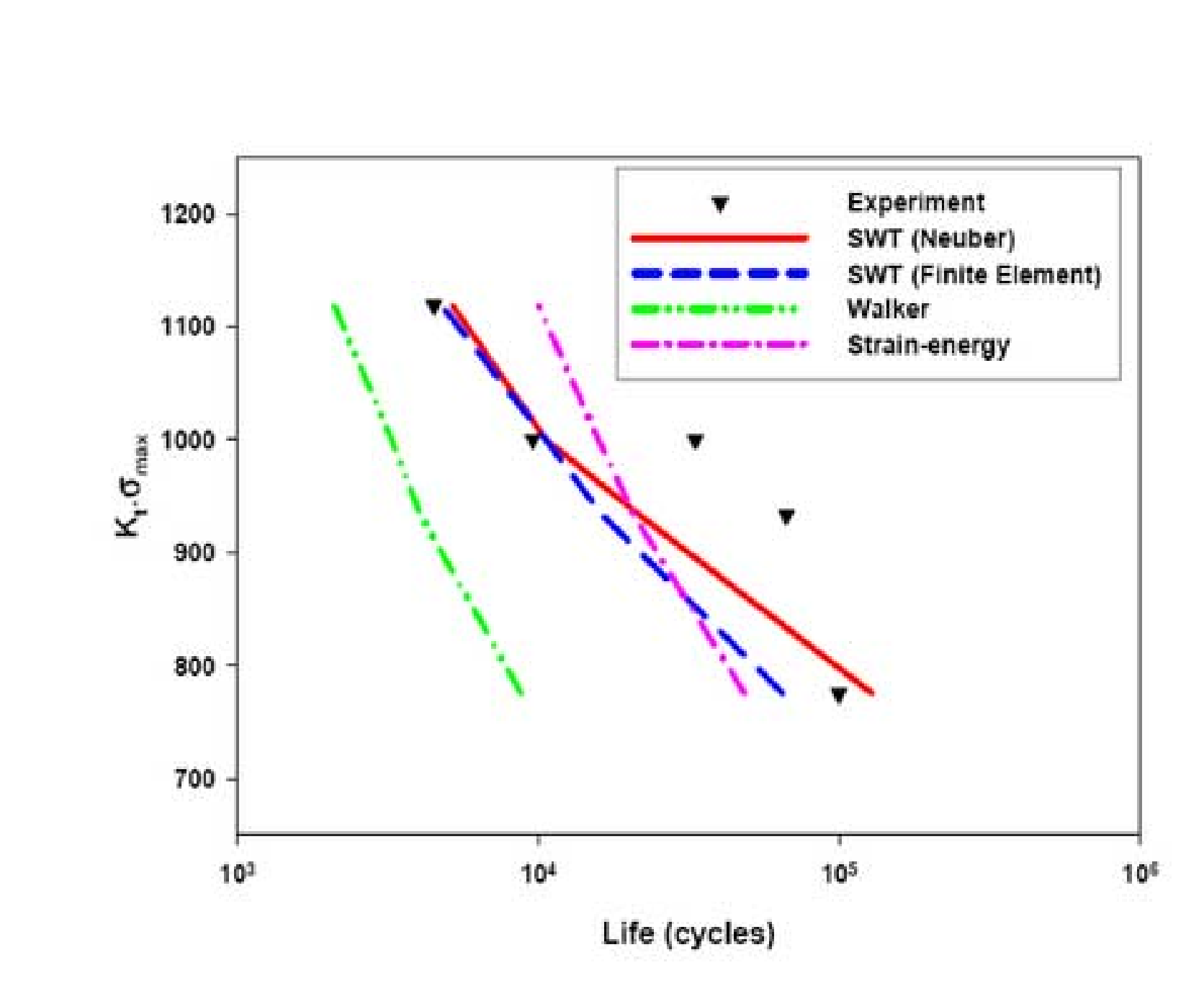

Figure 15: Various prediction methods at $500^{\circ} \mathrm{C}$
Click here to download high resolution image

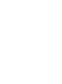

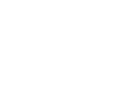

(2)

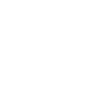

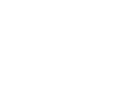

(2)

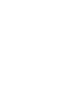

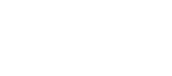

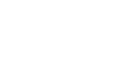

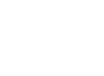

(2.
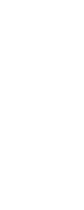

Life (cycles)

\begin{abstract}
-
\end{abstract}
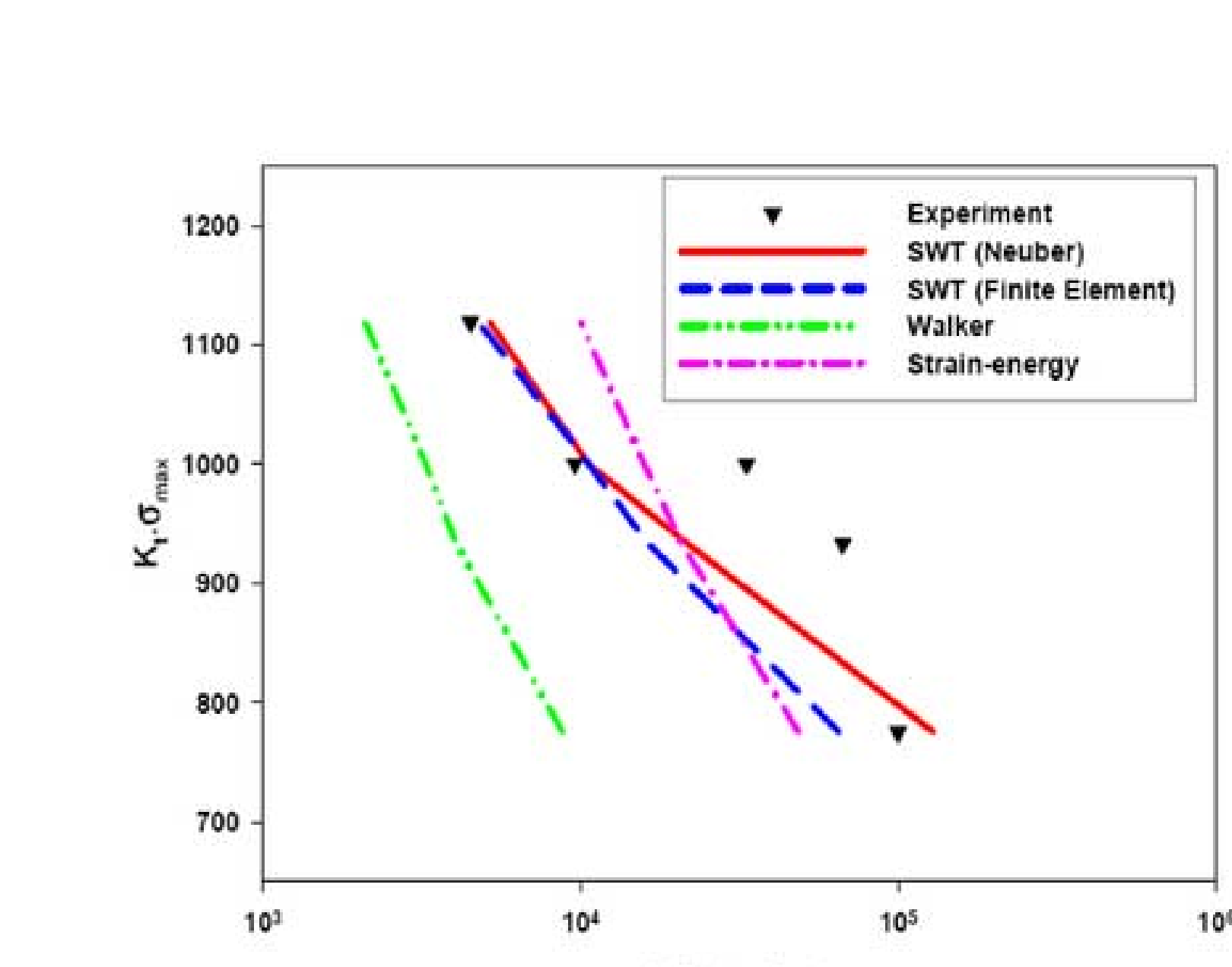